\title{
Social capital and under-utilization of medication for financial reasons among elderly women: evidence from two Brazilian health surveys
}

\author{
Capital social e subutilização de medicamentos por motivos \\ financeiros entre idosas: evidências de dois inquéritos brasileiros
}

Tatiana Chama Borges Luz ${ }^{1}$

Antônio Ignácio de Loyola Filho ${ }^{2}$

Maria Fernanda Lima-Costa ${ }^{2}$

${ }^{1}$ Laboratório de Educação em Saúde e Ambiente,

Centro de Pesquisas René

Rachou, Fundação Oswaldo Cruz. Av. Augusto de Lima 1715/Anexo, Barro Preto. 30.190-002 Belo Horizonte MG Brasil.

tatianachama@cpqrr.fiocruz.br

${ }^{2}$ Núcleo de Estudos em

Saúde Pública e

Envelhecimento, Fundação

Oswaldo Cruz.

\begin{abstract}
This cross-sectional study assesses the prevalence and examines the role of social and demographic factors, health conditions, health system characteristics and contextual factors of under-utilization of medication for financial reasons among elderly women. Participants in the Greater Metropolitan Belo Horizonte Health Survey $(G M B H)$ and the eleventh phase of the Bambui Cohort Study of the Elderly were assessed. Among elderly women in the GMBH, the prevalence of under-utilization was $11.4 \%$, and in Bambui, the rate was $5.4 \%$. Self-perception of health (OR, 3.46; 95\%CI, 1.32-9.10); daily life limitations (OR, 2.75; 95\% CI, 1.31-5.78) and perception of help (OR, 2.36; 95\% CI, 1.07-5.25) had independent associations with under-utilization among GMBH residents. A poor perception of both cohesion in the neighborhood (OR, 2.38; 95\% CI, 1.02-5.56) and the physical environment $(O R, 2.58$; 95\% CI, 1.10-6.03) significantly increased the likelihood of under-utilization among Bambuí residents. These results provide important clues to identifying possible risk factors for under-utilization, highlighting the need to develop strategies targeting the amplification of the involvement between elderly women and their community to reduce the extent of under-utilization in later life.

Key words Under-utilization for financial reasons, Social capital, Women, Elderly women, Pharmacoepidemiology
\end{abstract}

Resumo Este estudo transversal apresenta estimativas de prevalência e avalia o papel dos fatores sociodemográficos, condições de saúde, características do sistema de saúde e contextuais na subutilização de medicamentos por motivos financeiros entre as mulheres mais idosas. Participantes do Inquérito de Saúde da Região Metropolitana de Belo Horizonte $(\mathrm{RMBH})$ e do décimo primeiro seguimento do Estudo de Coorte de Idosos de Bambuí foram avaliadas. Na RMBH, a prevalência da subutilização foi de 11,4\%, e em Bambuí, foi de 5,4\%. Autopercepção de saúde (OR = 3,46; IC95\% =1,32-9,10); limitações da vida diária $(O R=2,75$; IC95\% = 1,31-5.78) e percepção de ajuda $(O R=$ 2,36; IC95\% = 1,07-5,25) apresentaram associações independentes com a subutilização para as residentes na $\mathrm{RMBH}$. Já a pior percepção de coesão ao bairro de moradia (OR = 2,38; IC95\% = 1,02-5,56) e a pior percepção do ambiente físico $(O R=2,58$; IC95\% = 1,10-6,03) aumentaram significativamente a chance de subutilização em Bambuí. Estes resultados apresentam importantes evidências na identificação de fatores de risco para a subutilização e apontam para a necessidade de desenvolver estratégias para ampliar a integração das idosas em sua comunidade de modo a reduzir o impacto da subutilização na velhice.

Palavras chave Subutilização por motivos financeiros, Capital social, Mulheres, Idosas, Farmacoepidemiologia 


\section{Introduction}

Cost-related medication nonadherence (CRN) e.g., not filling or taking a medication as prescribed because of drug cost - is fast becoming an important health issue in the geriatric population ${ }^{1-3}$. Previous studies, carried out to quantify the extent of this problem among the elderly in both developed and developing countries, have found rates of CRN ranging from $1.0 \%$ to $32 \% \%^{4-7}$.

Researches suggest that CRN is particularly problematic in people with disability or multiple comorbid disorders ${ }^{4-7}$; and in those without health insurance or prescription drug coverage ${ }^{5-}$ 6,8 . Other characteristics positively associated with CRN are female gender ${ }^{4,6}$, low income $e^{4-6,8}$, and racial or ethnic minority status ${ }^{6-7,9}$. Differences in adherence are also attributed to the quality of the physician-patient relationship ${ }^{5,10}$. Contextual factors may also contribute to CRN. We previously reported that low levels of social capital were linked to CRN among elderly ${ }^{11}$.

Nevertheless, little is known about how the burden of prescription drug cost is distributed across subgroup of the elderly population ${ }^{1,9}$. Most studies do not provide information on CRN among older women, especially for those aged 70 years and over. This is an important omission given that women in old age are highly vulnerable to poverty ${ }^{12,13}$, to experience higher levels of comorbidity and poorer health status ${ }^{14-16}$. Additionaly, comparing to their male counterparts, old women have the highest rates of prescription medication use and these rates increase with age ${ }^{3,15}$. Considering that two-thirds of the old women in the world are living in middle and low income countries $^{12}$, a special focus on this particular subgroup is worthwhile.

We sought to assess the prevalence of CRN among older women in two Brazilian communities setting and to investigate the rule of sociodemographic factors, health conditions, health system characteristics and contextual factors on CRN among these women.

\section{Methodology}

\section{Study areas}

The Greater Metropolitan Belo Horizonte $(\mathrm{GMBH})$, located in the state of Minas Gerais, is composed of around 20 municipalities, representing Brazil's third largest metropolitan area in both population (4.4 million inhabitants) and gross domestic product ${ }^{17}$. Bambuí is a small town (15,000 inhabitants), $240 \mathrm{~km}$ from GMBH, that has as main economic activities agriculture and small commerce ${ }^{18,19}$.

\section{Data Source}

Data were taken from the GMBH Health Survey and from the eleventh wave of Bambuí Study. Both studies were approved by the Institutional Review Board of the Oswaldo Cruz Foundation.

GMBH Health Survey was performed in 2003 and was based on a two-stage stratified cluster sample, using the Brazilian census tract as the primary selection unit and household as the sample unit. Residents aged 18 years or older were eligible for the survey. A total of 13,701 respondents completed the questionnaire $(1,778$ aged 60 years or older), yielding a response rate of $79 \%$. Participants' distribution by gender and age was similar to that observed among the total $\mathrm{GMBH}^{17}$.

The Bambuí Cohort Study of Ageing is a population-based cohort study of older adults. In the baseline cohort, assembled in 1997, all the inhabitants aged 60 years or older $(1,742$ inhabitants) were invited to take part in the study. A response rate of 92 per cent was achieved and 1,606 individuals were included ${ }^{18}$. This cohort is being followed up yearly. Questions on cost-related nonadherence (CRN) were added in the household survey in 2008 (wave XI of Bambuí study). From 1997 to 2007, 96 (6.0\%) cohort members were lost to follow-up. In 2008, 865 participants were alive and were selected to participate in the study (age $=70$ years or more).

More details on both studies can be found elsewere ${ }^{17-19}$.

\section{Study Design and Participants}

This study consists of cross-sectional analysis of both GMBH study and the eleventh wave of Bambuí Study, done separately for each survey. All the women, aged 70 years and over who needed prescribed medicines formed the subset for analysis ( $n=478$ in the GMBH survey and $n$ $=535$ in the Bambuí study).

\section{Outcome variable}

Cost-related nonadherence (CRN) was assessed by the following questions, based on preceding studies ${ }^{6,20}$ : "Thinking about the cost of the medicines prescribed to you in the past 30 days: (1) "Did you not fill a prescription because it was 
too expensive?"; (2) "Did you skipped doses to make the medicine last longer?"; (3) "Did you took smaller doses of a medicine to make the medicine last longer?". Affirmative response to at least one of these questions was considered CRN for the analysis purposes.

\section{Covariates}

We considered the following four groups of variables (domains) that were previously described as risk factors for $\mathrm{CRN}^{5,8,9,11,20,21}$ : (1) Sociodemographic characteristics: age, education, monthly personal income, marital status, household arrangements (living alone vs with others). (2) Health conditions: self-rated health, number of selected chronic conditions, reported limitations of activities of daily living (ADLs) and reported limitations of instrumental activities of daily living (IADL). The self-rated health status was measured by a single question, that has shown robust validity as well as good test-retest reliability ${ }^{22,23}$, as follows: "In the actual moment, how would you rate your health: (1) excellent; (2) good; (3) fair; (4) poor?". Response options were treated as a dichotomous variable categorized as "excellent/good" (0) and "fair/poor". For selected chronic conditions, we used a checklist of 8 conditions based on the report of previous medical diagnosis (arthritis/rheumatism, stroke, hypertension, diabetes mellitus, angina pectoris, myocardial infarction, heart disease and depression). An ADL limitation was defined as having any difficulty to perform at least one of the following activities: bathing, dressing, getting out of bed, walking from room to room, using the toilet or eating. An IADL limitation was defined as having any difficulty to perform at least one of the following activities: managing money, preparing meals and shopping. (3) Access and use of health care services: private health plan, number of doctor visits in the past 12 months, hospitalizations in the previous 12 months and having a regular doctor. Regular doctor was defined by three consecutive questions: If you have a health problem and decide to see a doctor, is there a physician to whom you normally go?, What is the doctor's name?, and How long has he/she been your doctor? The variable was considered positive if the interviewee answered "yes" to the first question, provided the doctor's name, and reported having consulted this physician for at least 12 months. (4) Individual-level social capital: this construct was covered by the following questions/ indexes (yes/no answer): Thinking of your neigh- borhood, would you say most people can be trusted?, assessing Neighborhood trust; Do you think that people in your neighborhood are willing to help each other? assessing Perception of help; Do you feel comfortable in your neighborhood, that is, do you feel at home?; Would you like to move out of this neighborhood? (question recoded in reverse order to ensure data consistency) and Do you think your neighborhood is a good place to you to live? Do you like your neighbors and your house?, creating a Perception of attachment to the neighborhood index. A composite variable was calculated to represent this index by adding the positive answers (Cronbach's alpha coefficients: 0.68 in GMBH study and 0.70 in Bambuí study). The range of answers for this index was $0-3$. High perception of attachment to the neighborhood was coded 0 and included the score 3 . Low perception of attachment to the neighborhood was coded 1 and included scores 0,1 and 2. Are you satisfied with how your neighborhood is being taken care of?, Do you think your neighborhood is a good place for children to play; and a good place to raise teenagers?, creating a Perception of physical environment index. A composite variable was calculated to represent this index by adding the positive answers (Cronbach's alpha coefficients: 0.48 in GMBH study and 0.43 in Bambuí study). The range of answers for this index was $0-2$. High perception of physical environment was coded 0 and included the score 2 . Low perception of physical environment was coded 1 and included scores 0 and 1 . The construction of social capital indexes was similar to Baron Epel et al. ${ }^{24}$. The estimated Cronbach's alpha coefficients showed a moderate to high reliability ${ }^{25}$.

\section{Statistical analyses}

Crude and multivariate analysis were based on Logistic Regression Analyses and on Pearson's Chi-Square test to explore the association between covariates and CRN (a binomial variable $0=$ no nonadherence due to cost; 1 = cost-related medication nonadherence, was used as the dependent variable). In every domain, covariates that had a p-value of 0.2 or less in the crude analysis were initially included in the multivariate models. A backward elimination process eliminated nonsignificant variables at the $\mathrm{p}$-value $<0.05$ level. The odds ratio (OR), 95\% confidence interval (CI) and p-value are presented.

Statistical analyses were performed using the software Stata, version 10.0 (StataCorp, College Station, Texas). Procedures from Stata for com- 
plex samples were used to analyze data from GMBH survey (Stata svy commands). For Bambuí study this procedure was not necessary, since this study was based on the total population.

\section{Results}

This study included 353 old women residing in the Greater Metropolitan Belo Horizonte and 518 old women residing in Bambuí (12.5\% of respondents in the GMBH and 3\% of respondents in Bambuí were excluded because they did not provide information on CRN). Participants and nonparticipants were similar in terms of mean age (77.8 years and 77.4 years, respectively, $\mathrm{p}=0.863$ in GMBH, and 78.1 years and 78.7 years, respectively, $\mathrm{p}=0.687$ in Bambuí).

The prevalence rates of CRN and the characteristics of the study participants are shown in Table 1. Among older women residing in the GMBH, the prevalence rate of CRN was $11.4 \%$ and for those residing in Bambuí, the corresponding value was $5.4 \%$. The following characteristics predominated in both studied population: monthly household income below two Brazilian minimum wages and $<7$ years of schooling. In terms of health, $62.1 \%$ and $48.3 \%$ of the women in the GMBH and in Bambuí, respectively, rated their health as fair/poor. Not having private health plan coverage was reported by the majority of the women $(53.9 \%$ in the GMBH and $72.0 \%$ in Bambuí). In relation to the social capital elements, approximately 1 in 4 of the respondents reported low perception of attachment to the neighborhood and about a half reported low neighborhood trust.

Table 2 shows the bivariate associations between CRN and sociodemographic characteristics. There was no difference between comparison groups in both studied populations.

Table 3 presents the bivariate associations between CRN and health conditions, access and use of health services. CRN was significantly $(\mathrm{p}<$ 0.05 ) more likely in women in the poorest selfrated health and with more self-reported chronic diseases, in both studied populations. Women in the GMBH with any ADL limitation were significantly $(\mathrm{p}<0.05)$ more likely to experience CRN than their counterparts. CRN was significantly $(p<0.05)$ more likely in women residing in the GMBH without private health plan coverage and with higher number of doctor visits in the past 12 months.

Table 1. Cost-related medication nonadherence status and characteristics of study participants. Greater Metropolitan, Belo Horizonte (GMBH Health Survey) and Bambuí Study.

\begin{tabular}{|c|c|c|}
\hline & GMBH $\quad n=353$ & BAMBUÍ $\quad \mathrm{n}=518$ \\
\hline Characteristic & Total $(\%)^{*}$ & Total $(\%)$ \\
\hline Cost-related medication nonadherence status (yes) & 11.4 & 5.4 \\
\hline Age, mean $(\mathrm{SD})$ & $77.4(6.3)$ & $78.1(5.9)$ \\
\hline Marital status (do not have a conjuge) & 76.6 & 79.9 \\
\hline Schooling $(<7$ years $)$ & 83.6 & 91.9 \\
\hline Monthly personal income $(<2)^{* *}$ & 77.5 & 81.2 \\
\hline Household structure (living alone) & 16.1 & 70.0 \\
\hline Self-rated health (fair /poor/) & 62.1 & 48.3 \\
\hline Number of self-reported chronic diseases $(>2)$ & 50.1 & 70.5 \\
\hline ADL limitation $(\text { yes })^{* * *}$ & 30.1 & 51.5 \\
\hline IADL limitation $(y e s)^{* * * *}$ & 47.0 & 58.8 \\
\hline Private health plan coverage (no) & 53.9 & 72.0 \\
\hline Hospitalizations in the previous 12 months (yes) & 18.2 & 21.9 \\
\hline Number of doctor visits in the past 12 months $(6+)$ & 38.2 & 25.3 \\
\hline Regular doctor (no) & 43.6 & 37.7 \\
\hline Neighborhood trust (low) & 51.5 & 44.8 \\
\hline Perception of help (no) & 22.2 & 10.7 \\
\hline Perception of attachment to the neighborhood (low) & 25.3 & 23.2 \\
\hline Perception of physical environment (low) & 19.8 & 28.7 \\
\hline
\end{tabular}

" Figures corrected by sampling weights. ${ }^{*}$ in times the monthly Brazilian minimum wage (during the studies period, total = US\$ 85.00 in the GMBH study and total = US\$250.00 in the Bambuí study). ${ }^{* * *}$ ADL are activities of daily living (bathing, dressing, transferring, using the toilet of eating). ${ }^{* * * *}$ IADL are instrumental activities of daily living (shopping, managing money and preparing meals). 
With reference to social capital elements, among GMBH residents, CRN was significantly $(\mathrm{p}<0.05)$ more likely only in women with no perception of help. Conversely, among Bambuí residents, CRN was significantly $(\mathrm{p}<0.05)$ more likely in women with low perception of attachment to the neighborhood and low perception of physical environment (Table 4).

Significant results $(\mathrm{p}<0.05)$ of the multivariate analysis of factors associated with CRN are presented in Table 5. Among GMBH residents, fair or poor health status (odds ratio [OR], 3.46; confidence interval [95\% CI], 1.32-9.10); any ADL limitation (OR, 2.75; 95\% CI, 1.07-5.78) and no perception of help (OR, 2.36; 95\% CI, 1.07-5.25) had the strongest effect on the likelihood of CRN. Contrasting, among Bambuí residents, low perception of attachment to the neighborhood (OR, 2.38; 95\% CI, 1.02-5.56) and low perception of physical environment (OR, 2.58; 95\% CI, 1.106.03) increased significantly the likelyhood of CRN.

\section{Discussion}

The prevalence of CRN among the older women residing in GMBH was more than two times greater than that observed among Bambuí residents. The reasons for greater nonadherence among GMBH residents cannot be directly ascertained from these data, but it is possible that Bambuí, due to its smaller size, offer a better environment for the construction of social capital which in turn reduces de prevalence of CRN. Alternatively, it is also possible that they may be due to interstudy differences. Contrary to GMBH study, seniors in Bambuí study are being followed up yearly and at each annual follow-up interview, questions on medication use are asked. Perhaps, this yearly evaluation of medication intake, enhance the interviewees's propensity to adhere to their prescribed treatment, reducing the likelihood of CRN.

The multivariate analysis reveals that low levels of social capital and poor health were associated with CRN in old Brazilian women. Among GMBH's women, $\mathrm{CRN}$ was more pronounced in

Table 2. Bivariate association between sociodemographic characteristics and cost-related medication nonadherence among elderly women. Greater Metropolitan, Belo Horizonte (GMBH Health Survey) and Bambuí Study.

\begin{tabular}{|c|c|c|c|c|}
\hline \multirow[b]{2}{*}{ Sociodemographic characteristics } & \multicolumn{2}{|c|}{ GMBH } & \multicolumn{2}{|r|}{ BAMBUÍ } \\
\hline & $\% \mathrm{CRN}^{*}$ & OR $(95 \% C I)$ & $\% \mathrm{CRN}$ & OR $(95 \% C I)$ \\
\hline \multicolumn{5}{|l|}{ Age (years ) } \\
\hline $70-79$ & 57.8 & Ref & 82.1 & Ref \\
\hline $80+$ & 42.2 & $\begin{array}{c}1.69(0.79-3.66) \\
(\mathrm{p}=0.819)\end{array}$ & 17.9 & $\begin{array}{c}0.39(0.15-1.06) \\
(\mathrm{p}=0.056)\end{array}$ \\
\hline \multicolumn{5}{|l|}{ Marital status } \\
\hline Has a conjuge & 27.5 & Ref & 17.9 & Ref \\
\hline No & 72.5 & $\begin{array}{c}0.78(0.32-1.91) \\
(\mathrm{p}=0.731)\end{array}$ & 82.1 & $\begin{array}{c}1.16(0.43-3.14) \\
\quad(p=0.763)\end{array}$ \\
\hline \multicolumn{5}{|l|}{ Schooling (years) } \\
\hline $0-7$ & 90.6 & Ref & 92.9 & Ref \\
\hline $8+$ & 9.4 & $\begin{array}{c}0.50(0.14-1.77) \\
(\mathrm{p}=0.219)\end{array}$ & 7.1 & $\begin{array}{c}0.86(0.20-3.78) \\
(\mathrm{p}=0.847)\end{array}$ \\
\hline \multicolumn{5}{|l|}{ Monthly personal income ${ }^{* *}$} \\
\hline$<2$ & 89.4 & Ref & 92.9 & Ref \\
\hline Higher & 10.6 & $\begin{array}{c}0.38(0.13-1.06) \\
\quad(p=0.161)\end{array}$ & 7.1 & $\begin{array}{c}0.32(0.74-1.36) \\
\quad(p=0.105)\end{array}$ \\
\hline \multicolumn{5}{|l|}{ Household structure } \\
\hline Living with others & 81.7 & Ref & 17.9 & Ref \\
\hline No & 18.3 & $\begin{array}{c}1.19(0.47-3.01) \\
(\mathrm{p}=0.746)\end{array}$ & 82.1 & $\begin{array}{c}2.04(0.76-5.46) \\
(p=0.150)\end{array}$ \\
\hline
\end{tabular}

OR, odds ratio; 95\%CI, 95\% confidence interval; p-value from Pearson chi-square test. * percentages corrected by sampling weights. ${ }^{* *}$ in times the monthly Brazilian minimum wage (during the studies period, total = US\$ 85.00 in the GMBH study and total = US\$250.00 in the Bambuí study). 
Table 3. Bivariate association between health conditions, access and use of health care services and cost-related medication nonadherence among elderly women. Greater Metropolitan, Belo Horizonte (GMBH Health Survey) and Bambuí Study.

\begin{tabular}{|c|c|c|c|c|}
\hline \multirow[b]{2}{*}{ Characteristics } & \multicolumn{2}{|r|}{ GMBH } & \multicolumn{2}{|r|}{ BAMBUÍ } \\
\hline & $\% \mathrm{CRN}^{*}$ & OR $(95 \% C I)$ & $\% \mathrm{CRN}$ & OR $(95 \% C I)$ \\
\hline \multicolumn{5}{|l|}{ Health Conditions } \\
\hline \multicolumn{5}{|l|}{ Self-rated health } \\
\hline Excellent-good & 14.9 & Ref & 28.6 & Ref \\
\hline Fair-poor & 85.1 & $\begin{array}{l}3.95(1.52-10.28) \\
\quad(p=0.007)\end{array}$ & 71.4 & $\begin{array}{c}2.83(1.23-6.58) \\
\quad(p=0.011)\end{array}$ \\
\hline \multicolumn{5}{|c|}{ Number of self-reported chronic diseases } \\
\hline$\leq 1$ & 29.2 & Ref & 10.7 & Ref \\
\hline$>2$ & 70.8 & $\begin{array}{l}2.64(1.22-5.73) \\
\quad(p=0.010)\end{array}$ & 89.3 & $\begin{array}{l}3.68(1.10-12.36) \\
\quad(p=0.025)\end{array}$ \\
\hline \multicolumn{5}{|l|}{ Any ADL limitation ${ }^{* *}$} \\
\hline No & 47.9 & Ref & 46.4 & Ref \\
\hline Yes & 52.1 & $\begin{array}{c}2.90(1.38-6.07) \\
(p=0.004)\end{array}$ & 53.6 & $\begin{array}{c}1.09(0.51-2.35) \\
(\mathrm{p}=0.818)\end{array}$ \\
\hline \multicolumn{5}{|l|}{ Any IADL limitation ${ }^{* * *}$} \\
\hline No & 46.3 & Ref & 42.9 & Ref \\
\hline Yes & 52.7 & $\begin{array}{c}1.29(0.62-2.69) \\
(\mathrm{p}=0.491)\end{array}$ & 57.1 & $\begin{array}{c}0.93(0.43-2.01) \\
(\mathrm{p}=0.852)\end{array}$ \\
\hline \multicolumn{5}{|l|}{ Access and use of health services } \\
\hline \multicolumn{5}{|l|}{ Private health plan coverage } \\
\hline Yes & 31.7 & Ref & 14.3 & Ref \\
\hline No & 68.3 & $\begin{array}{c}1.99(0.92-4.33) \\
\quad(p=0.047)\end{array}$ & 85.7 & $\begin{array}{c}2.42(0.83-7.11) \\
\quad(p=0.097)\end{array}$ \\
\hline \multicolumn{5}{|c|}{ Hospitalizations in the previous 12 months } \\
\hline No & 20.9 & Ref & 78.6 & Ref \\
\hline Yes & 79.1 & $\begin{array}{l}1.22(0.52-2.85) \\
\quad(p=0.645)\end{array}$ & 21.4 & $\begin{array}{c}0.97(0.38-2.45) \\
\quad(p=0.946)\end{array}$ \\
\hline $\begin{array}{l}\text { Number of doctor visits in the } \\
\text { months }\end{array}$ & 51.0 & Ref & 82.1 & Ref \\
\hline $\begin{array}{l}\leq 5 \\
6+\end{array}$ & 49.0 & $\begin{array}{c}1.65(0.78-3.46) \\
(p=0.035)\end{array}$ & 17.9 & $\begin{array}{c}0.63(0.23-1.68) \\
\quad(p=0.349)\end{array}$ \\
\hline Regular doctor & 46.4 & Ref & 50.0 & Ref \\
\hline Yes & 53.6 & $1.57(0.79-3.27)$ & 50.0 & $1.70(0.79-3.65)$ \\
\hline No & & $(\mathrm{p}=0.220)$ & & $(\mathrm{p}=0.168)$ \\
\hline
\end{tabular}

OR, odds ratio; 95\%CI, 95\% confidence interval; p-value from Pearson chi-square test. * : percentages corrected by sampling weights. ${ }^{* *} \mathrm{ADL}$ are activities of daily living (bathing, dressing, transferring, using the toilet of eating); ${ }^{* *} \mathrm{IADL}$ are instrumental activities of daily living (shopping, managing money and preparing meals).

those with no perception of help and in poor health. On the other hand, among women residing in Bambuí, low perception of attachment to the neighborhood and low perception of physical environment contributed independently to CRN.

The indicators of worse health status in GMBH, that were found to be associated with $\mathrm{CRN}$, are in line with the literature ${ }^{1,6,8}$ and raise additional concerns, since access to medications may be particularly important for preventing further deterioration in health status ${ }^{8}$.
The most important finding from this research is the significant association between social capital and CRN. To the best of our knowledge, other investigators have not previously considered social capital as a provable determinant of CRN. However, this result confirms our prior study's findings that low levels of social capital appear to be associated with CRN ${ }^{11}$. It should be noted, however, that in that study we included elderly aged 60 years or older and both male and female subjects, while in the current study we have 
Table 4. Bivariate association between individual measures of social capital and cost-related medication nonadherence among elderly women. Greater Metropolitan, Belo Horizonte (GMBH Health Survey) and Bambuí Study.

\begin{tabular}{|c|c|c|c|c|}
\hline \multirow[b]{2}{*}{ Individual Measures of Social Capital } & \multicolumn{2}{|c|}{ GMBH } & \multicolumn{2}{|c|}{ BAMBUÍ } \\
\hline & $\% \mathrm{CRN}^{*}$ & OR $(95 \% \mathrm{CI})$ & $\% \mathrm{CRN}$ & OR $(95 \% \mathrm{CI})$ \\
\hline \multicolumn{5}{|l|}{ Neighborhood trust } \\
\hline High & 45.3 & Ref & 50.0 & Ref \\
\hline Low & 54.7 & $\begin{array}{c}1.15(0.56-2.41) \\
(p=0.697)\end{array}$ & 50.0 & $\begin{array}{c}1.24(0.58-2.68) \\
\quad(p=0.570)\end{array}$ \\
\hline \multicolumn{5}{|l|}{ Perception of help } \\
\hline Yes & 61.4 & Ref & 85.7 & Ref \\
\hline No & 38.6 & $\begin{array}{c}2.52(1.13-5.61) \\
\quad(p=0.020)\end{array}$ & 14.3 & $\begin{array}{c}1.43(0.48-4.30) \\
\quad(p=0.523)\end{array}$ \\
\hline \multicolumn{5}{|l|}{ Perception of attachment to the neighborhood } \\
\hline High & 62.3 & Ref & 40.7 & Ref \\
\hline Low & 37.7 & $\begin{array}{c}1.85(0.85-4.07) \\
\quad(p=0.119)\end{array}$ & 59.3 & $\begin{array}{c}3.63(1.68-7.88) \\
\quad(p=0.001)\end{array}$ \\
\hline \multicolumn{5}{|l|}{ Perception of physical environment } \\
\hline High & 80.6 & Ref & 44.4 & Ref \\
\hline Low & 19.4 & $\begin{array}{c}0.97(0.34-2.76) \\
\quad(p=0.957)\end{array}$ & 55.6 & $\begin{array}{c}3.47(1.58-7.64) \\
\quad(p=0.001)\end{array}$ \\
\hline
\end{tabular}

OR, odds ratio; 95\%CI, 95\% confidence interval; p-value from Pearson chi-square test; " percentages corrected by sampling weights.

Table 5. Statistically significant results for the multivariate analysis of the associated factors with cost-related medication nonadherence among elderly women. Greater Metropolitan Belo Horizonte (GMBH Health Survey) and Bambuí Study.

\begin{tabular}{|c|c|c|}
\hline Characteristics & $\begin{array}{c}\text { GMBH } \\
\text { OR }(95 \% C I)\end{array}$ & $\begin{array}{c}\text { BAMBUÍ } \\
\text { OR }(95 \% C I)\end{array}$ \\
\hline \multicolumn{3}{|l|}{ Self-rated health } \\
\hline Excellent-good & Ref & \\
\hline Fair-poor & $3.46(1.32-9.10)$ & \\
\hline \multicolumn{3}{|l|}{ Any ADL limitation ${ }^{\mathrm{a}}$} \\
\hline No & Ref & \\
\hline Yes & $2.75(1.31-5.78)$ & \\
\hline \multicolumn{3}{|l|}{ Perception of help } \\
\hline Yes & Ref & \\
\hline No & $2.36(1.07-5.25)$ & \\
\hline \multicolumn{3}{|c|}{ Perception of attachment to the neighbourhood } \\
\hline High & & Ref \\
\hline Low & & $2.38(1.02-5.56)$ \\
\hline \multicolumn{3}{|l|}{ Perception of physical environment } \\
\hline Yes & & Ref \\
\hline No & & $2.58(1.10-6.03)$ \\
\hline
\end{tabular}

OR, odds ratio; 95\%CI, 95\% confidence interval; estimated by logistic regression and adjusted for all the variables listed in the column. Reference group: individuals who reported no CRN. a Activities of daily living (bathing, dressing, transferring, using the toilet of eating).

focused on two subgroup of old women aged 70 years or more, one living in Belo Horizonte and the other in Bambuí.
The pathways by which social capital might improve adherence to medical treatment are, however, unclear. It is possible that social capital oper- 
ate through its influence on transmission of health information, on health-related behaviors - such as adherence to prescribed medication - on social control over deviant health-related behavior and on improved access to health services and resourc$\mathrm{es}^{26}$, which include pharmaceutical provision. Additionally, it has been suggested that the effects of the sentiments of not belonging to a community, of not having social support and of living in deprived areas can be particularly detrimental for old women's health, since they are more distressed by community deterioration than old $\mathrm{men}^{27}$. This fact may perhaps explain the lower rates of CRN in neighborhoods with high levels of social capital.

We also have note significant differences among the forms of social capital associated with $\mathrm{CRN}$ in the studied populations. In GMBH, women with no perception of help have odds nearly 2.4 times higher of reporting CRN than those which no such perception. Meanwhile, in Bambuí the odds of CRN were almost 2.4 times higher in women with low perception of attachment to the neighborhood and 2.6 times higher in those with low perception of physical environment. The reasons for these differences require specifically targeted research to explore further, but they seem consistent with the theorization that there are complex cultural and social interactions which may influence the relationship between social capital and health within a country ${ }^{28,29}$.

In our study, low income and lack of health insurance could not explain CRN. Even the link between CRN and heavy disease burden ${ }^{1,6,20}$ was detected mixed: this association was found in GMBH, but not in Bambuí. On the surface, these findings would seem to contradict some reports $^{1,6,8}$. On the other hand, some authors have argued that the relationship between the costs of prescription medication and adherence is a complex behavior, since many patients continue using their medication as prescribed even facing high medication costs, low incomes, and lack of prescription medication coverage ${ }^{9,20}$. Our results, in fact, reinforce the idea that the people's way of thinking and acting is mediated by the social and cultural context to which they belong ${ }^{30}$, so even populations that share similar vulnerabilities e.g. being old and female - can behave very differently regarding to their prescribed medication.

A few limitations of this study should be acknowledged. This study is a cross-sectional in design thus the analysis reveals association rather than temporal relationships. Regarding the comparability of results, the research instruments were similar in both surveys. For the choice of the ex- ploratory variables we considered a wide variety of potential determinants of CRN obtained from the literature ${ }^{1,5,6,20}$. Researches suggest that the physician relationships rated by patients as high quality and trustworthy greatly decreased the likelihood of $\mathrm{CRN}^{5,10}$, however, information on this was not available in the Bambuí study. We assessed one alternative variable (e.g., regular doctor), which characterizes continuity of care ${ }^{31}$ and is associated with improved patient's trust in the provider $^{32}$, but we found no evidence of a relationship between regular doctor and CRN.

There is no consensus regarding the definition of social capital, its exact components or whether it is a property of individuals or collectives, particularly in the context of public health ${ }^{33,34}$. In addition, there is no 'gold standard' measure of social capital and all methods that have been employed to assess this complex construct have their limitations $s^{33}$. This study is concerned with providing a multidimensional approach of social capital that was designed to mirror previous literature ${ }^{24,35-37}$. Although without statistical significance in the bivariate analysis, the associations between social capital elements and CRN were consistent with the hypothesis that lower levels of social capital increases de likelihood of CRN. Moreover, the multivariate findings, reinforced by our previous research ${ }^{11}$, suggests a strong evidence of an independent effect of social capital elements on CRN.

This study has some advantages. Our findings are based on two population-based studies with high response rates. Data losses were only $3 \%$ in Bambuí and an acceptable $12.5 \%$ in the GMBH. We estimated that approximately $75 \%$ of the elderly aged 70 and over living in Bambuí are enrolled in the cohort study. Thus, there are no strong reasons to believe in any serious selection bias.

Our work support and extend the limited existing literature on $\mathrm{CRN}$, providing unique data on the characterization of CRN among older women. Our results provided important clues to identifying possible risk factors for CRN, highlighting the need to consider social capital influences on CRN. Our results also indicate that, among older women, differences of prevalence and factors associated with CRN can be found in the same country, probably due to sociocultural influences. From a public policy perspective, these results may provide useful information for developing strategies targeting the amplification of the involvement between the elderly and their community to reduce the extent of CRN in later life. 


\section{Collaborations}

TCB Luz was responsible for the conception, planning, analysis and interpretation of the results of the study and drafting the manuscript. AI Loyola Filho contributed with the interpretation of the results and revision of the manuscript content. MF Lima-Costa participated in the interpretation of data and revision of the manuscript content. All authors critically revised and approved the final manuscript

\section{Acknowledgements}

This study was supported by grants from $\mathrm{CNPq}$, FINEP and FAPEMIG.

\section{References}

1. Briesacher BA, Gurwitz JH, Soumerai SB. Patients at-risk for cost-related medication nonadherence: a review of the literature. J Gen Intern Med 2007; 22(6):864-871.

2. Piette JD, Heisler M, Horne R, Caleb Alexander G. A conceptually based approach to understanding chronically ill patients' responses to medication cost pressures. Soc Sci Med 2006; 62(4):846-857.

3. Kaufman DW, Kelly JP, Rosenberg L, Anderson TE, Mitchell AA. Recent patterns of medication use in the ambulatory adult population of the United States - The Slone Study. JAMA 2002; 287(3):337-344.

4. Zivin K, Ratliff S, Heisler MM, Langa KM, Piette JD. Factors influencing cost-related nonadherence to medication in older adults: a conceptually based approach. Value Health 2010; 13(4):338-345

5. Luz TCB, Loyola Filho AI, Lima-Costa MF. Estudo de base populacional da subutilização de medicamentos por motivos financeiros entre idosos na Região Metropolitana de Belo Horizonte, Minas Gerais, Brasil. Cad Saude Publica 2009; 25(7):15781586.

6. Soumerai SB, Pierre-Jacques M, Zhang F, RossDegnan D, Adams AS, Gurwitz J, Adler G, Safran DG. Cost-related medication nonadherence among elderly and disabled Medicare beneficiaries: a national survey 1 year before the Medicare drug benefit. Arch Intern Med 2006; 166(17):1829-1835

7. Taira DA, Iwane KA, Chung RS. Prescription Drugs: Elderly Enrollee Reports of Financial Access Receipt of Free Samples and Discussion of Generic Equivalents Related to Type of Coverage. Am J Manag Care 2003; 9(4):305-312.

8. Klein D, Turvey C, Wallace R. Elders who delay medication because of cost: health insurance demographic health and financial correlates. Gerontologist 2004; 44(6):779-787.

9. Steinman MA, Sands LP, Covinsky KE. Self-restriction of medications due to cost in seniors without prescription coverage. J Gen Intern Med 2001; 16(12): 793-799.

10. Piette JD, Heisler M, Krein S, Kerr EA. The role of patient-physician trust in moderating medication nonadherence due to cost pressures. Arch Int Med 2005; 165(15):1749-1755.

11. Luz TCB, Loyola Filho AI, Lima-Costa MF. Perceptions of social capital and cost-related non-adherence to medication among the elderly. Cad Saude Publica 2011; 27(2):269-276.

12. World Health Organization (WHO). Women and health: today's evidence tomorrow's agenda. Geneva: WHO; 2009. [Internet]. [cited 2010 Feb 10]. Available from: http://whqlibdoc.who.int/publications/2009/9789241563857_eng.pdf

13. Rosenberg MW, Wilson K. Gender, poverty and location: how much diference do they make in the geography of health inequalities? Soc Sci Med 2000; 51(2):275-287.

14. Sixsmith A, Sixsmith J, Green S, Kennedy V. Enable-age survey study. WP3 National Report, United Kingdom, 2004. [Internet]. [cited 2010 Feb 10]. Available from: http://www.enableage. arb.lu.se/documents/WP $3 \% 20$ National $\% 20$ Report\%20T1\%20UK.pdf 
15. Jörgensen T, Johansson S, Kennerfalk A, Wallander MA, Svärdsudd K. Prescription drug use, diagnoses, and healthcare utilization among the elderly. Ann Pharmacother 2001; 35(9):1004-1009.

16. Arber S, Cooper H. Gender differences in health in later life: The new paradox? Soc Sci Med 1999; 48(1):61-78.

17. Lima-Costa MF. A saúde dos adultos na Região Metropolitana de Belo Horizonte: um estudo epidemiológico de base populacional. Belo Horizonte: Núcleo de Estudos em Saúde Pública e Envelhecimento, Fundação Oswaldo Cruz, Universidade Federal de Minas Gerais; 2004.

18. Lima-Costa MF, JO Firmo, Uchoa E. Cohort Profile: The Bambuí (Brazil) Cohort Study of Ageing. Int J Epidemiol 2011; 40(4):862-867.

19. Lima-Costa MF, Uchoa E, Guerra HL, Firmo JA, Vidigal PG, Barreto MSM. The Bambuí Health and Ageing Study (BHAS): methodological approach and preliminary results of a population based cohort study of the elderly in Brazil. Rev Saude Publica 2000; 34(2):126-135.

20. Piette JD, Heisler M, Wagner TH. Cost-related medication underuse among chronically ill adults: the treatments people forgo, how often, and who is at risk. Am J Public Health 2004; 94(10):1782-1787.

21. Soumerai SB, Pierre-Jacques M, Zhang F, Ross-Degnan D, Adams AS, Gurwitz J, Adler G, Safran DG. Cost-related medication non-adherence among elderly and disabled Medicare beneficiaries: a national survey 1 year before the Medicare drug benefit. Arch Intern Med 2006; 166(17):1829-1835.

22. Martikainen P, Aromaa A, Heliovaara M, Klaukka T, Knekt P, Maatela J, Lahelma E. Reliability of perceived health by sex and age. Soc Sci Med 1999; 48(8):1117-1122

23. Balkrishnan R, Anderson RT. Predictive power of a risk-assessment questionnaire across different disease states: results in an elderly managed care enrolled population. Am J Manag Care 2001; 7(2):145153.

24. Baron-Epel O, Weinstein R, Haviv-Mesika A, GartySandalon N, Green MS. Individual-level analysis of social capital and health: a comparison of Arab and Jewish Israelis. Soc Sci Med 2008; 66(4):900-910.

25. Schultz J, O’Brien AM, Tadesse B. Social capital and self-rated health: results from the US 2006 social capital survey of one community. Soc Sci Med 2008; 67(4):606-617.

26. Kawachi I, Kennedy BP, Glass R. Social capital and self-rated health: a contextual analysis. Am J Public Health 1999; 89(9):1187-1193.

27. Phillipson C, Bernard M, Phillips J, Ogg J. Older people's experiences of community life: Patterns of neighbouring in three urban areas. Sociol Rev 1999; 47(4):715-743.
28. Mansyur C, Amick BC, Harrist RB, Franzini L. Social capital, income inequality, and self-rated health in 45 countries. Soc Sci Med 2008; 66(1):43-56.

29. Lynch J, Smith GD, Hillemeier M, Shaw M, Raghunathan T, Kaplan G. Income inequality, the psychosocial environment, and health: comparisons of wealthy nations. Lancet 2001; 358(9277):194-200.

30. Uchôa E, Vidal JM. Antropologia médica: elementos conceituais e metodológicos para uma abordagem da saúde e da doença. Cad Saude Publica 1994; 10(4):497-504.

31. Forrest CB, Starfield B. Entry into primary care and continuity: The effects of access. Am J Public Health 1998; 88(9):1330-1336.

32. Mainous AG 3rd, Baker R, Love MM, Gray DP, Gill JM. Continuity of care and trust in one's physician: evidence from primary care in the United States and the United Kingdom. Fam Med 2001; 33(1):22-27.

33. Nieminen T, Martelin T, Koskinen S, Simpura J, Alanen E, Härkänen T, Aromaa A. Measurement and socio-demographic variation of social capital in a large population-based survey. Soc Indic Res 2008; 85(3):405-423.

34. Macinko J, Starfield B. The Utility of Social Capital in Research on Health Determinants. Milbank Q 2001; 79(3):387-427.

35. Pampalon R, Hamel D, De Koninck M, Disant MJ. Perception of place and health: differences between neighbourhoods in the Québec City region. Soc Sci Med 2007; 65(1):95-111.

36. Araya R, Dunstan F, Playle R, Thomas H, Palmer S, Lewis G. Perceptions of social capital and built environment and mental health. Soc Sci Med 2006; 62(12):3072-3083.

37. Hyyppä MT, Mäki J. Individual-level relationships between social capital and self-rated health in a bilingual community. Prev Med 2001; 32(2):148-155.

Artigo apresentado em 21/07/2012

Aprovado em 28/08/2012

Versão final apresentada em 03/09/2012 